\title{
Deformation and fracture of explosion-welded Ti/Al plates: a synchrotron-based study
}

\author{
J. C. E ${ }^{\mathrm{a}, \mathrm{b}}$, J. Y. Huang ${ }^{\mathrm{a}, \mathrm{c}}$, B. X. Bie ${ }^{\mathrm{a}, \mathrm{d}}$, T. Sun ${ }^{\mathrm{e}}$, K. Fezzaa ${ }^{\mathrm{e}}$, X. H. Xiao ${ }^{\mathrm{e}}$, W. Sun ${ }^{\mathrm{f}}$, S. N. Luo ${ }^{\mathrm{a}, \mathrm{b}, *}$ \\ ${ }^{a}$ The Peac Institute of Multiscale Sciences, Chengdu, Sichuan 610031, P. R. China \\ ${ }^{b}$ Key Laboratory of Advanced Technologies of Materials, Ministry of Education, Southwest Jiaotong University, Chengdu, Sichuan 610031, P. R. China \\ ${ }^{c}$ CAS Key Laboratory of Materials Behavior and Design, Department of Modern Mechanics, University of Science and Technology of China, Hefei, Anhui 230027, \\ P. R. China \\ ${ }^{d}$ School of Science, Wuhan University of Technology, Wuhan, Hubei 430070, P. R. China \\ ${ }^{e}$ Advanced Photon Source, Argonne National Laboratory, Argonne, Illinois 60439, USA \\ ${ }^{f}$ School of Ocean Science and Technology, State Key Laboratory of Structural Analysis for Industrial Equipment, Dalian University of Technology, Panjin 124000, \\ Liaoning, P. R. China
}

\begin{abstract}
Explosion-welded Ti/Al plates are characterized with energy dispersive spectroscopy and x-ray computed tomography, and exhibit smooth, well-jointed, interface. We perform dynamic and quasi-static uniaxial tension experiments on Ti/Al with the loading direction either perpendicular or parallel to the Ti/Al interface, using a mini split Hopkinson tension bar and a material testing system in conjunction with time-resolved synchrotron x-ray imaging. X-ray imaging and strain-field mapping reveal different deformation mechanisms responsible for anisotropic bulk-scale responses, including yield strength, ductility and rate sensitivity. Deformation and fracture are achieved predominantly in Al layer for perpendicular loading, but both $\mathrm{Ti}$ and $\mathrm{Al}$ layers as well as the interface play a role for parallel loading. The rate sensitivity of Ti/Al follows those of the constituent metals. For perpendicular loading, single deformation band develops in Al layer under quasi-static loading, while multiple deformation bands nucleate simultaneously under dynamic loading, leading to a higher dynamic fracture strain. For parallel loading, the interface impedes the growth of deformation and results in increased ductility of Ti/Al under quasi-static loading, while interface fracture occurs under dynamic loading due to the disparity in Poisson's contraction.
\end{abstract}

Keywords: explosion welding, dynamic tensile loading, XCT, XDIC

\section{Introduction}

Multilayered composites, such as mollusk shells in nature, usually possess unique mechanical and chemical properties [13]. Man-made jointed Ti/Al has been widely used in aerospace 5 and automobile industries, for its high specific strength and considerable ductility [4-6]. Impact is commonly encountered in such applications, and dynamic deformation and failure of Ti/Al bimetal plates are thus important for better structural de- ${ }^{30}$ sign and safe guarding [7-11].

$\mathrm{Ti}$ and $\mathrm{Al}$ are dissimilar metals, and are difficult to be jointed through conventional welding methods such as diffusion bonding, cold rolling and pressure welding [12]. Explosive welding has shown its strong capability in joining a variety of dissimi- ${ }^{35}$ lar metals, including Ti and Al [13-16]. Moreover, explosive welding can produce joints with high bond strength over large welding areas, and minimal distortion of parent metals. Extensive studies have been devoted to microstructural characterization of welding interfaces, e.g., wavy patterns, intermetallic ${ }^{40}$ compositions and defects $[14,15,17]$. Three-dimensional $\mathrm{x}$ -

20 ray computed tomography (XCT) has been widely utilized as a powerful, non-destructive, tool in microstructure characterization of various materials, e.g., composites, foams, granular ma-

\footnotetext{
${ }^{*}$ Corresponding author

Email address: sluo@pims.ac.cn (S. N. Luo )
}

terials and similar welding metals, with $\mu \mathrm{m}$ spatial resolution [18-22]. However, XCT characterization of the weld between dissimilar metals has been scarcely reported.

Dynamic mechanical properties of explosion-welded $\mathrm{Ti} / \mathrm{Al}$ plates have been rarely investigated. For dynamic tension loading, split Hopkinson tension bar (SHTB) has been widely used [23-25]. Strain gages are effective for obtaining bulk, rather than meso-scale, responses. Local deformation dynamics can be characterized with 2D strain field mapping, using optical digital image correlation $[26,27]$ or $\mathrm{x}$-ray digital image correlation (XDIC) [24, 28, 29]. XDIC is advantageous for the penetration capabilities of $\mathrm{X}$-rays, and relies on images acquired with such techniques as $\mathrm{x}$-ray phase contrast imaging [21, 30, 31], particularly useful in resolving damage and cracking of low-Z, optically opaque, materials $[25,30]$. Weld or bimetal interface may play a key role in material performance. For example, formation of brittle intermetallic phases may degrade mechanical properties of welding materials [32-34]. However, in situ measurements on dynamic strain distributions across the interface with high-speed XDIC are extremely rare. Mesoscopic deformation dynamics of explosion-welded bimetal plates including Ti/Al subjected to impact loading, is essentially untouched.

In the present study, XCT and energy dispersive spectroscopy (EDS) are utilized to characterize the initial microstructures of explosion-welded Ti/Al interface. A mini split Hopkin- 
(a)
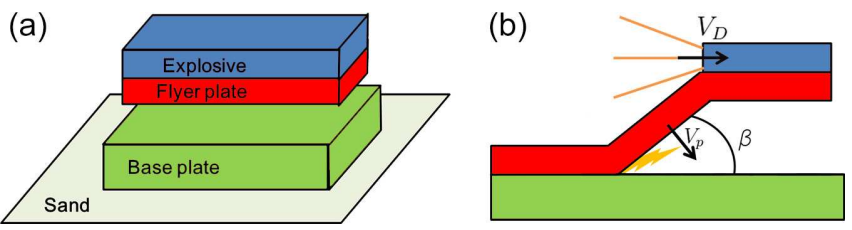

Figure 1: Schematic illustration of setup (a) and process (b) of explosive welding. In (a), Ti and $\mathrm{Al}$ plates are set parallel to each other with a stand-off between them. An explosive charge is placed on the surface of the flyer plate (Ti). In (b), $V_{\mathrm{D}}$ is the velocity of detonation front, $V_{\mathrm{p}}$ is the impact velocity of flyer plate, and $\beta$ is the collision angle.

son tension bar (SHTB) and material test system (MTS), implemented with in situ, high-speed XDIC, are used to obtain and quasi-static loading, respectively. Stress-strain curves are measured, together with strain fields of deforming Ti/Al samples loaded either parallel or perpendicular to the interface. The x-ray imaging and strain field mapping demonstrate pro$\mathrm{Ti} / \mathrm{Al}$ samples. This study also provides insights into strain-rate effects, strength and ductility of Ti/Al bimetal plates, and likely, other layered composites.

\section{Experimental}

\subsection{Materials}

Ti plates are TC4 titanium alloy (Ti6Al4V), and Al plates 100 are LY12 aluminum alloy (AlCu4Mg1). Ti/Al bilayer plates are manufactured by explosive welding, as schematically illustrated in Fig. 1. Ti and Al plates are set parallel to each other with a stand-off between them. An explosive charge is placed on the surface of the flyer plate (Ti), and is set off with a det-105 onator. After detonation of the explosive charge, a detonation front travels along the charge at a velocity of $V_{\mathrm{D}}$. The detonation wave propels the flyer plate to impact on the base plate (Al) at a velocity of $V_{\mathrm{p}}$. The impact velocity $V_{\mathrm{p}}$ and collision angle $\beta$ determine the normal and shear stress at the welding ${ }_{110}$ zone, which have significant influence on the morphology of the welding interface $[35,36]$.

Composition and morphology of the Ti/Al interface are ex75 amined with EDS. The EDS map (Fig. 2(a)) shows no obvious pores or cracks across the interface. A small piece of Ti (the ${ }_{115}$ arrow) protrudes into the $\mathrm{Al}$ matrix, probably due to rapid pressure boost and intense plastic deformation during welding [37]. Such island morphology is widely observed when the detonation force and metal vortex flow are high [15]. The amplitude of the saw-tooth features of the Ti/Al interface is about $3.67 \mu \mathrm{m}, 120$ much smaller than those reported in other explosive-welding materials $(\sim 100 \mu \mathrm{m})[15,38]$. The amplitude of the wavy interface structure is directly related to the collision angle [35]. The x-ray tomography (Fig. 2(b)) obtained at the beamline 2-BM of the Advanced Photon Source, and the topography reconstructed ${ }_{125}$ from the tomography, reveal 3D nature of the $\mathrm{Ti} / \mathrm{Al}$ interface (Figs. 2(c) and (d)). The maximum height difference of the interface is $19.52 \mu \mathrm{m}$, and the root mean square height difference (a)

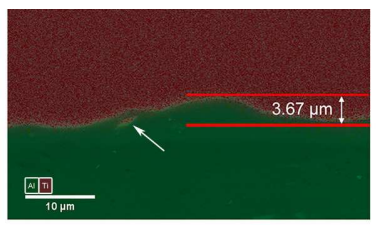

(b)

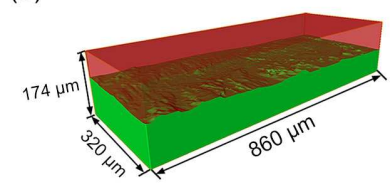

(c)

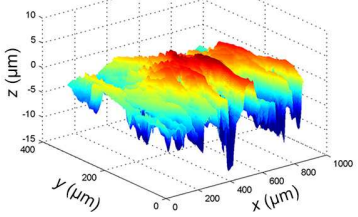

(d)

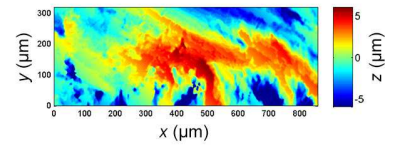

Figure 2: Characterization of the Ti/Al interface. (a) EDS map. (b) 3D tomography. (c) 3D topography extracted from the tomography. (d) Topography map, i.e., a top view of (c).

or roughness [38] is $2.68 \mu \mathrm{m}$, consistent with the EDS result (Fig. 2(a)).

\subsection{Loading setups}

We implement mini SHTB (dynamic) and MTS (quasi-static) loading devices along with a high-speed $\mathrm{x}$-ray imaging system 95 at the beamline 32-ID of the Advanced Photon Source, and the schematic setups are shown in Fig. 3(a). Relevant experimental details have been presented elsewhere [24, 28, 30, 39]. The launch tube of a conventional SHTB is modified (Fig. 3(b)) for synchrotron radiography test. In the conventional design [23], a ring striker is in direct contact with the incident bar, which may pull the incident bar and the sample out of the field of view during launch due to friction. Thus, a sleeve (B) is used to physically separate the incident bar (A) and striker (C) to prevent pre-movement of the bar and sample. A Teflon ring (D) is installed to support the striker and seal gas inside the launch tube $(\mathrm{E})$.

As shown in Fig. 3(a), a Ti/Al sample (4) is held between two steel collets (6). Two kinds of samples are prepared for loading applied either parallel (Ti/Al-0) or perpendicular (Ti/Al-90) to the Ti/Al interface. The samples are dog-bone shaped, with gauge lengths of $3 \mathrm{~mm}$ and $2 \mathrm{~mm}$ for Ti/Al-90 and Ti/Al-0, respectively; the thickness along the $\mathrm{x}$-ray direction is $500 \mu \mathrm{m}$. The striker (2), incident bar (1), and transmission bar (5) are all made of high-strength steel, with a diameter of $6 \mathrm{~mm}$. After the gas gun is fired, the striker impacts the flange fixed to the incident bar end and generates an elastic tensile wave propagating through the incident bar along the $x$-direction. When the incident wave arrives at the interface between the incident bar and sample, it is partially reflected owing to impedance mismatch, while the rest is transmitted into the transmission bar. The highspeed camera (9) is triggered by the strain gages attached to the incident bar upon arrival of the incident wave. During loading, the $\mathrm{x}$-rays transmitted through the Ti/Al sample form images on the scintillator (8) which are captured by the high-speed camera (9) as image sequences. The transmitted waves are recorded by strain gages attached to the transmission bar. The incident and transmitted waves are used to derive the stress $\sigma_{\mathrm{s}}(t)$, strain $\varepsilon_{\mathrm{s}}(t)$ and strain-rate $\dot{\varepsilon}_{\mathrm{s}}(t)$ histories of the sample with following 


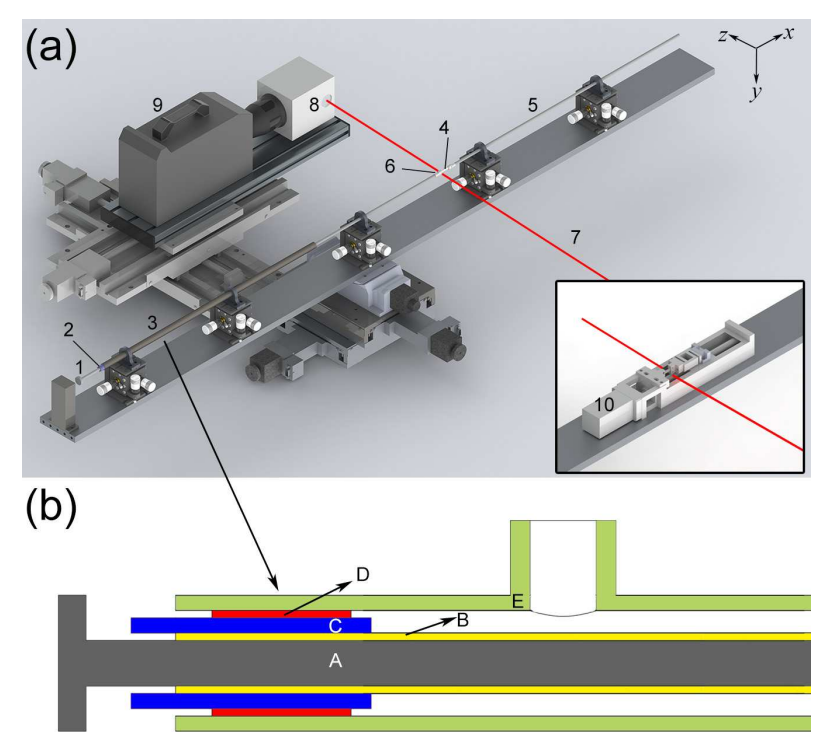

Figure 3: (a) Schematic of mini SHTB (1-9) and MTS (10) experiments with time-resolved $x$-ray imaging. 1: incident bar; 2 : striker; 3 : launch tube; 4: sample; 5: transmission bar; 6: collet; 7: x-ray beam; 8: scintillator and reflecting mirrors; 9: high-speed camera; 10: mini MTS. (b) Details of the SHTB launch tube. A: incident bar; B: sleeve; C: striker; D: Teflon ring; E: outer tube.

equations [40]:

$$
\begin{aligned}
& \sigma_{\mathrm{s}}=E_{\mathrm{t}} \varepsilon_{\mathrm{t}} \frac{A_{\mathrm{t}}}{A_{\mathrm{s}}}, \\
& \dot{\varepsilon}_{\mathrm{s}}=\frac{2 C_{0}}{L_{\mathrm{s}}}\left(\varepsilon_{\mathrm{t}}-\varepsilon_{\mathrm{i}}\right), \\
& \varepsilon_{\mathrm{s}}=\frac{2 C_{0}}{L_{\mathrm{s}}} \int_{0}^{t}\left(\varepsilon_{\mathrm{t}}-\varepsilon_{\mathrm{i}}\right) d \tau,
\end{aligned}
$$

where $E$ is the Young's modulus, $A$ is the cross-sectional area, and $C_{0}$ is the sound velocity of bar materials. $L_{\mathrm{S}}$ is the gage $\mathrm{i}, \mathrm{t}$ and $\mathrm{s}$ denote the incident bar, transmission bar and sample, respectively. Here $E_{\mathrm{t}}=200 \mathrm{GPa}$, and $C_{0}=5000 \mathrm{~m} \mathrm{~s}^{-1}$. For comparison, quasi-static experiments are also performed with a mini MTS (10) as shown in the inset of Fig. 3(a).

\section{Results and discussions}

\subsection{Stress-strain curves and $x$-ray imaging}

Schematics of two kinds of Ti/Al samples are shown in the inset of Fig. 4. Dynamic and quasi-static loading are applied to these $\mathrm{Ti} / \mathrm{Al}$ samples, as well as their constituent materials ${ }_{180}$ curves are presented in Fig. 4 for different materials (Ti/Al-0, $\mathrm{Ti} / \mathrm{Al}-90, \mathrm{Ti}$ and $\mathrm{Al}$ ) under different strain rates (quasi-static versus dynamic). For clarity, the stress-strain curves of Ti and $\mathrm{Al}$ under quasi-static loading are not shown.

The stress-strain curves of Ti/Al samples are located between those of $\mathrm{Ti}$ and $\mathrm{Al}$ samples, as expected from the general mixture rule of composite materials [41]. However, Ti/Al0 samples exhibit quite different mechanical responses from

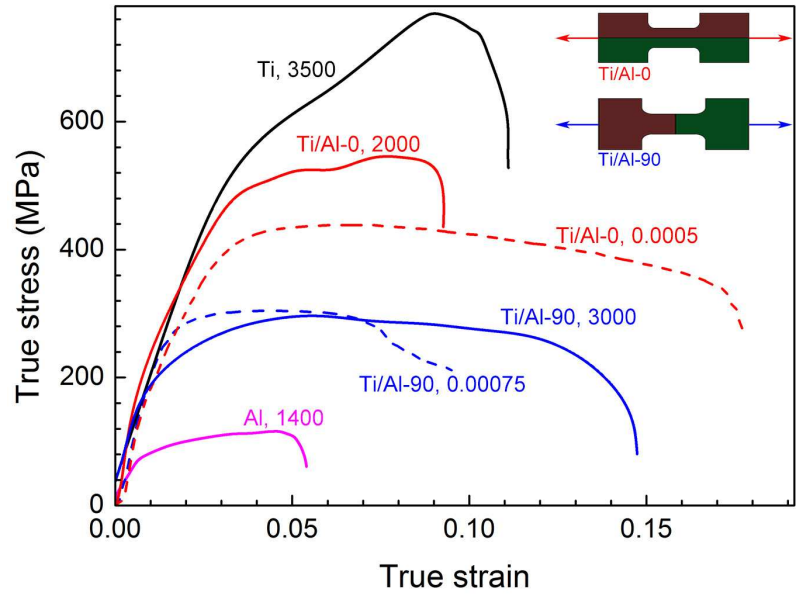

Figure 4: True stress-strain curves of Ti-Al-90, Ti-Al-0, Ti and Al under tension via SHTB and MTS loading. Numbers denote strain rate in $\mathrm{s}^{-1}$. Ti/Al-90 and $\mathrm{Ti} / \mathrm{Al}-0$ refer to the loading directions perpendicular and parallel to the $\mathrm{Ti} / \mathrm{Al}$ interface, respectively (inset).

Ti/Al-90 samples. The stress-strain curves of Ti/Al-0 samples appear above those of Ti/Al-90 samples. Ti/Al-0 samples exhibit considerable strain-rate effects, while the stressstrain curves of Ti/Al-90 samples under dynamic and quasistatic loading are "similar." Ti/Al-90 samples fracture at a strain of 0.12 under dynamic loading which is much higher than the fracture strain of 0.062 under quasi-static loading. Under a similar strain rate $\left(\sim 0.0005 s^{-1}\right), \mathrm{Ti} / \mathrm{Al}-0$ samples fracture at a strain of 0.17 , much higher than that of Ti/Al-90 samples (0.062). High-speed image sequences are obtained with x-ray phase contrast imaging during dynamic tension. The framing rate is set at $100,000 \mathrm{~Hz}$ and the exposure time is set as $0.35 \mu \mathrm{s}$. For quasi-static loading, the framing rate is set at $10 \mathrm{~Hz}$. The spatial resolution is about $4 \mu \mathrm{m}$. The central area $(\sim 2 \mathrm{~mm} \times 1$ $\mathrm{mm}$ ) of the sample is chosen for imaging. The snapshots for different samples at different loading rates are shown in Figs. 5-8. For the Ti/Al samples, the Ti layer appears darker in the $\mathrm{x}$-ray images than the $\mathrm{Al}$ layer because of the difference in $\mathrm{x}$-ray absorption, so the Ti/Al interface can be clearly resolved. XDIC is used to map the strain fields of sample areas marked with red rectangles in the images. Strain maps are obtained between neighboring frames.

\subsection{Tension perpendicular to the interface (Ti/Al-90)}

The true stress-strain curve of a Ti/Al-90 sample under quasi-static loading is presented in Fig. 5(a), along with the dynamic loading curve for comparison. Overall, the stress-strain curves of Ti/Al-90 samples are similar to those for $\mathrm{Al}$, which show perfect plasticity and negligible sensitivity to strain rates $[42,43]$. For such a loading geometry, the stress across the $\mathrm{Ti}$ and $\mathrm{Al}$ layers is the same before necking occurs [41]. The $\mathrm{x}$-ray images show that deformation and fracture mainly takes place in the Al layer; a macrocrack results in the eventual failure (Fig. 5(b)).

At frames $\mathrm{f} 1$ and $\mathrm{f} 2$, strain distributions are homogeneous in both the Ti and Al layers (Fig. 5(c)). However, at frame f3, pronounced tensile $\left(E_{x x}\right)$ and shear $\left(E_{x y}\right)$ strain localizations occur 
(a)

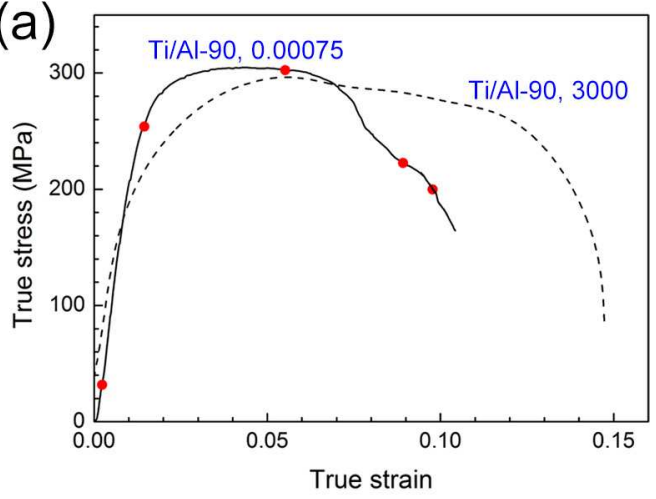

(c)

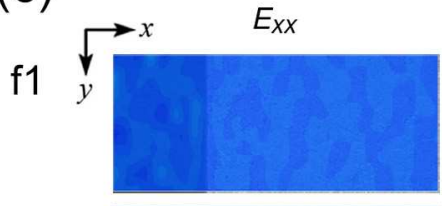

f2

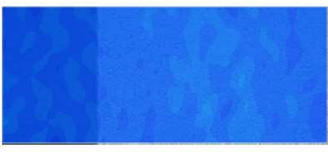

f3

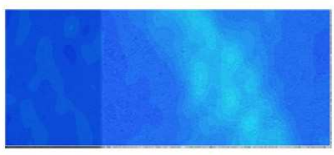

f4

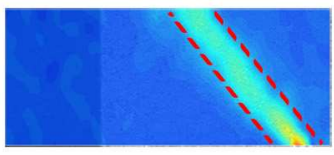

f5

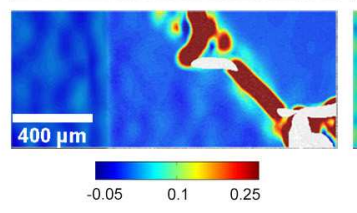

(b)

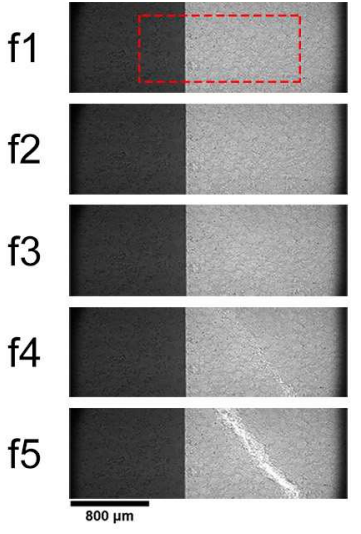

$E_{x y}$
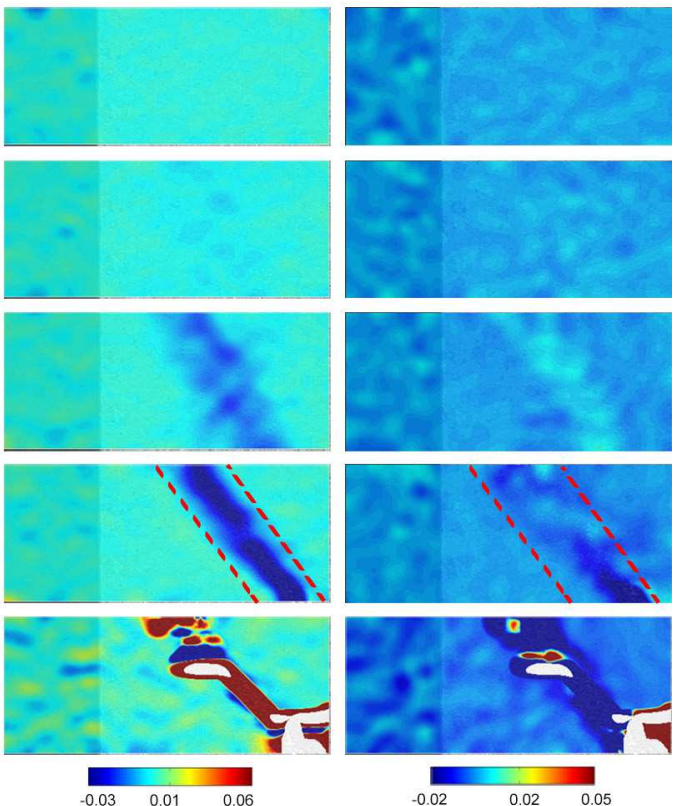

(d)

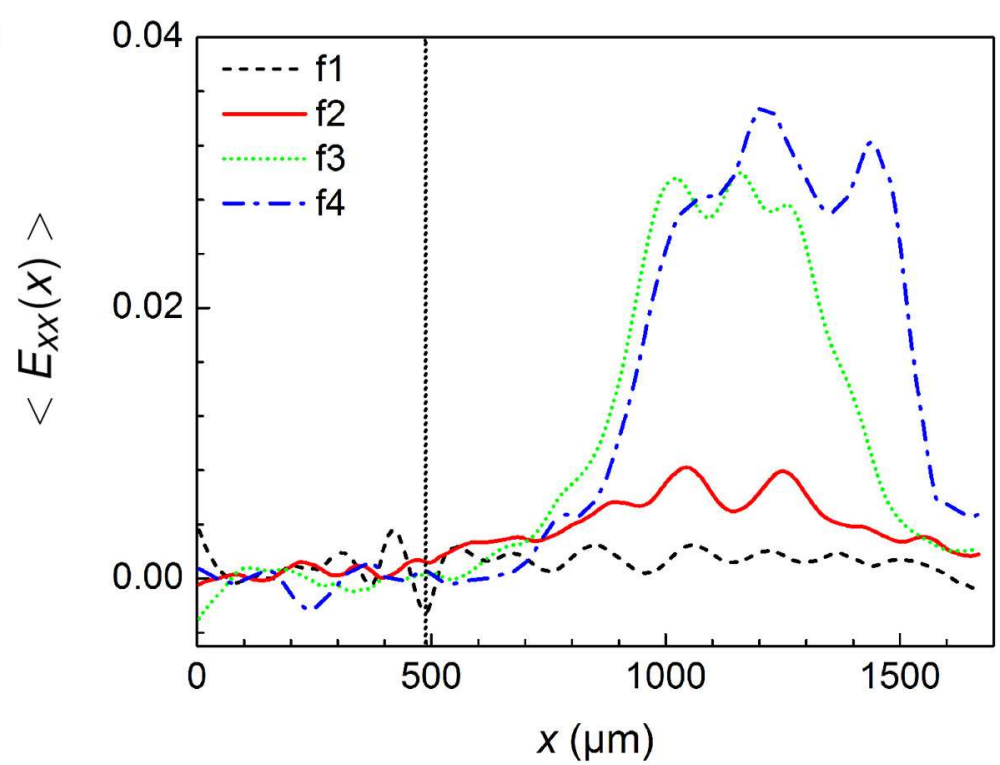

Figure 5: Quasi-static tension perpendicular to the Ti/Al interface (Ti/Al-90). (a) True stress-strain curve (the high-strain rate curve is also included for comparison). Numbers denote strain rate in $\mathrm{s}^{-1}$. (b) Snapshots at the instants marked with dots in (a). (c) $2 \mathrm{D}$ strain fields $E_{x x}, E_{y y}$ and $E_{x y}$. (d) $\left\langle E_{x x}(x)\right\rangle$ profiles across the interface, corresponding to the region denoted by the rectangle in (b). The vertical dotted line indicates the Ti/Al interface. 
(a)

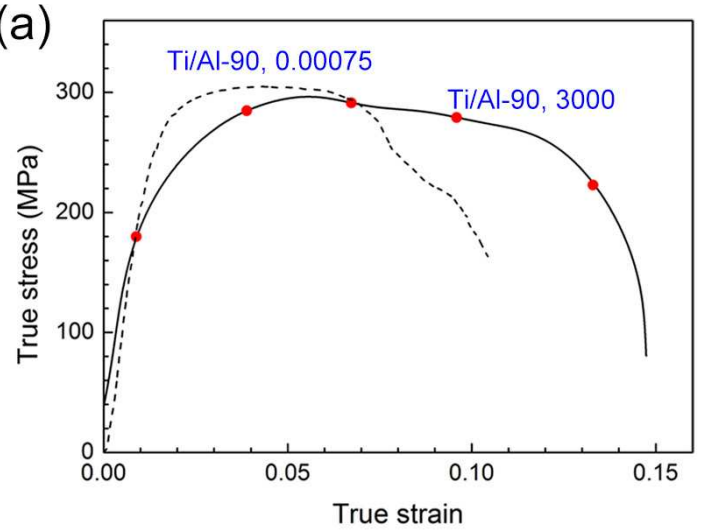

(c)

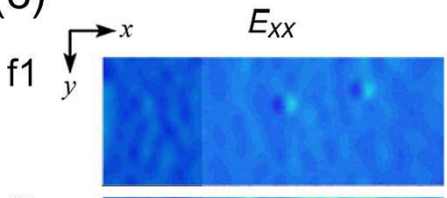

f2

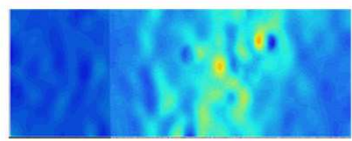

f3

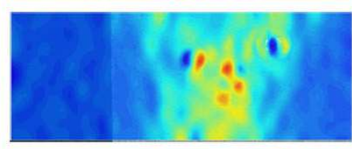

f4

f5
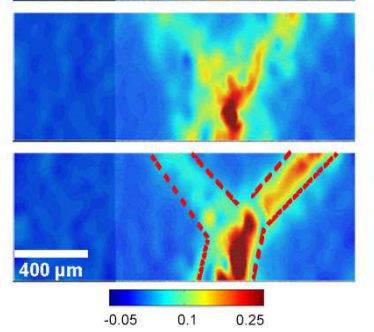

$E_{y y}$ (b)
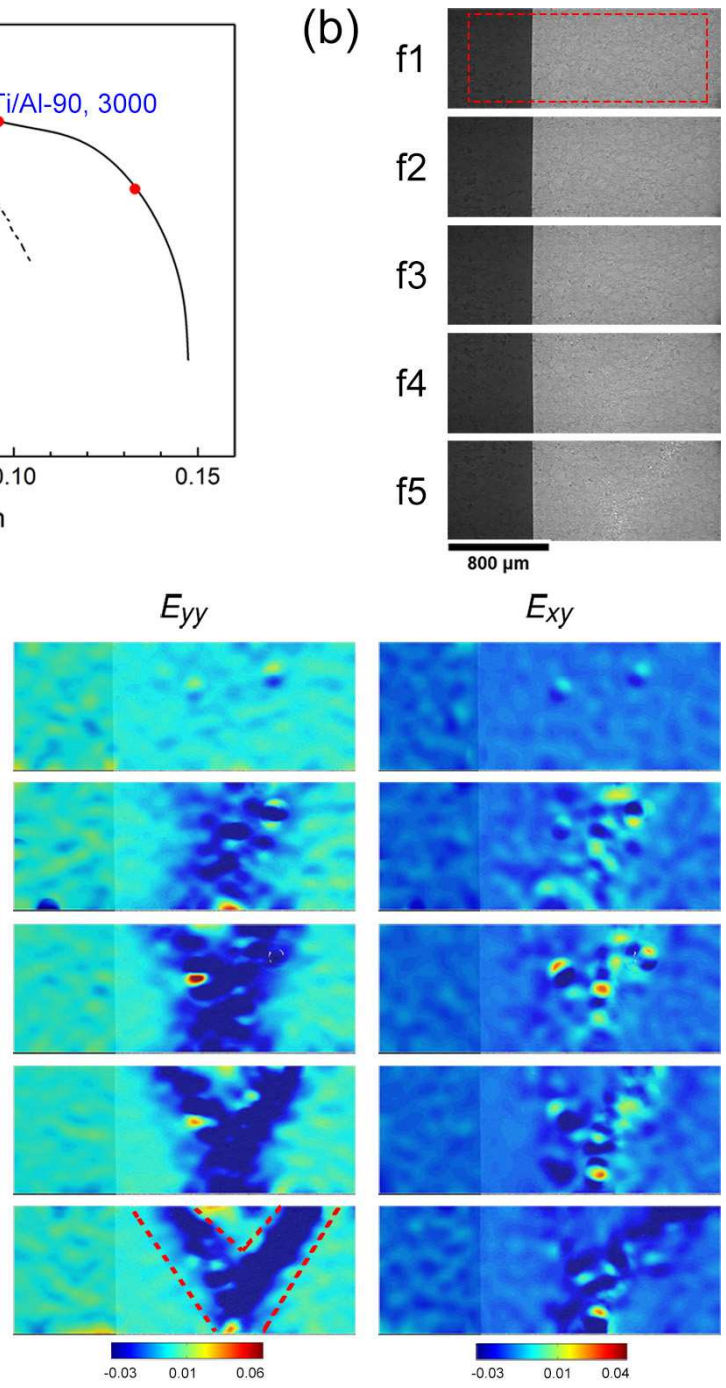

(d)

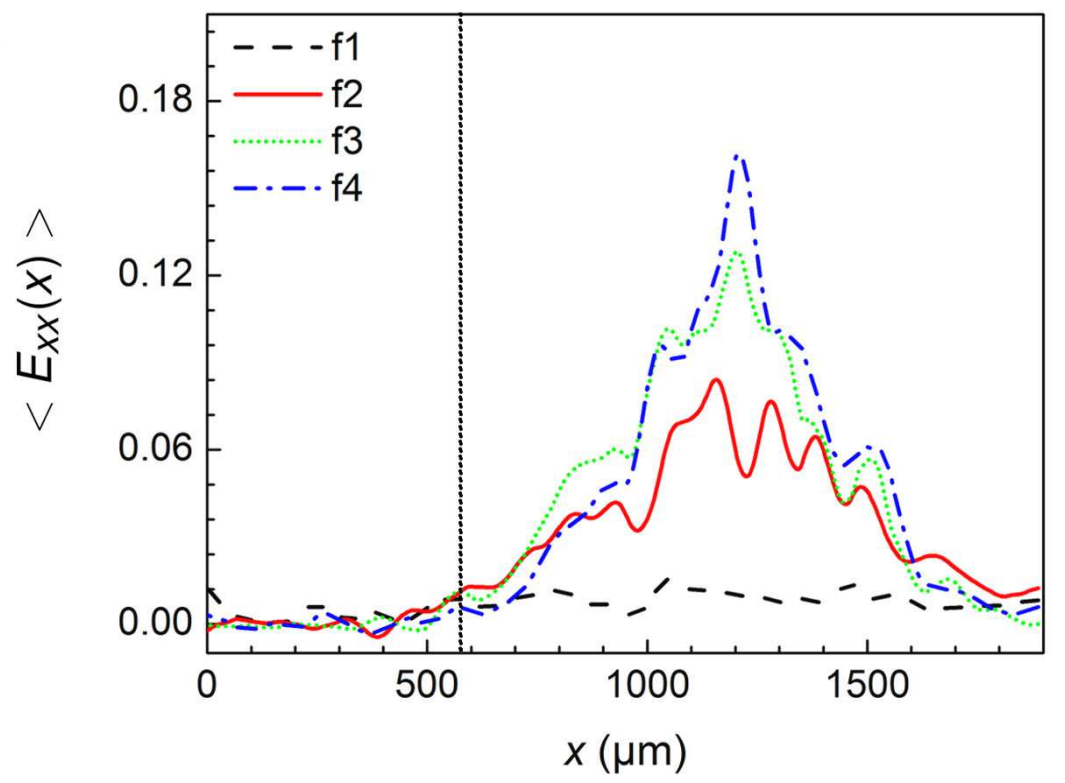

Figure 6: Dynamic tension perpendicular to the Ti/Al interface (Ti/Al-90). (a) True stress-strain curve (the quasi-static curve is also included for comparison). Numbers denote strain rate in $\mathrm{s}^{-1}$. (b) Snapshots at instants marked in (a). (c) $2 \mathrm{D}$ strain fields $E_{x x}, E_{y y}$ and $E_{x y}$. (d) $\left\langle E_{x x}(x)\right\rangle$ profiles across the interface, corresponding to the region denoted by the rectangle in (b). The vertical dotted line indicates the Ti/Al interface. 
(a)

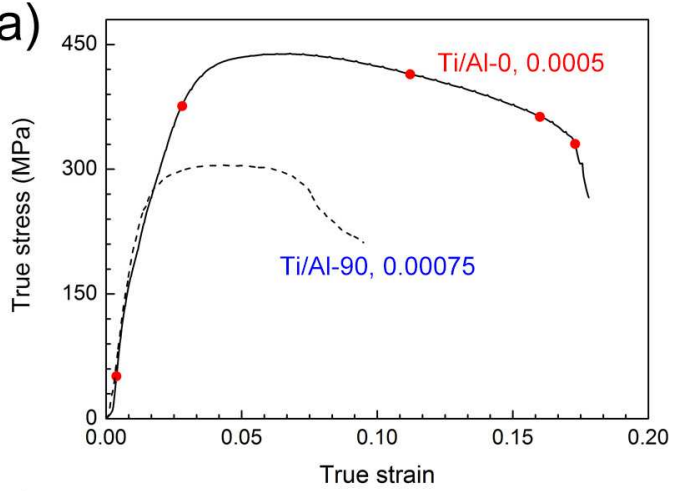

(c)

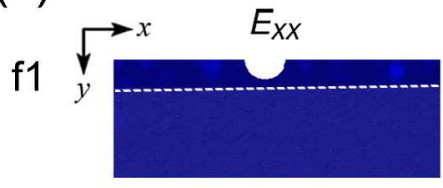

f2

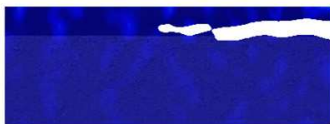

f3

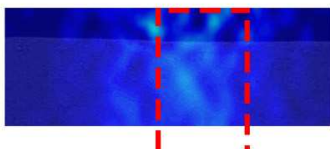

f4

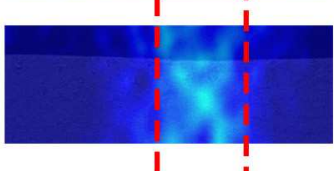

f5

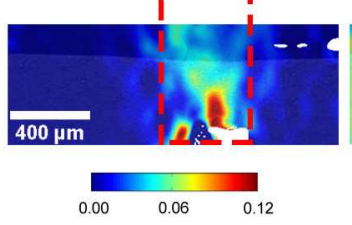

(b)

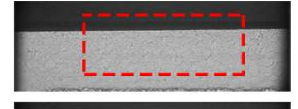

f2

f3

f4

f5

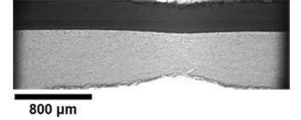

$E_{x y}$
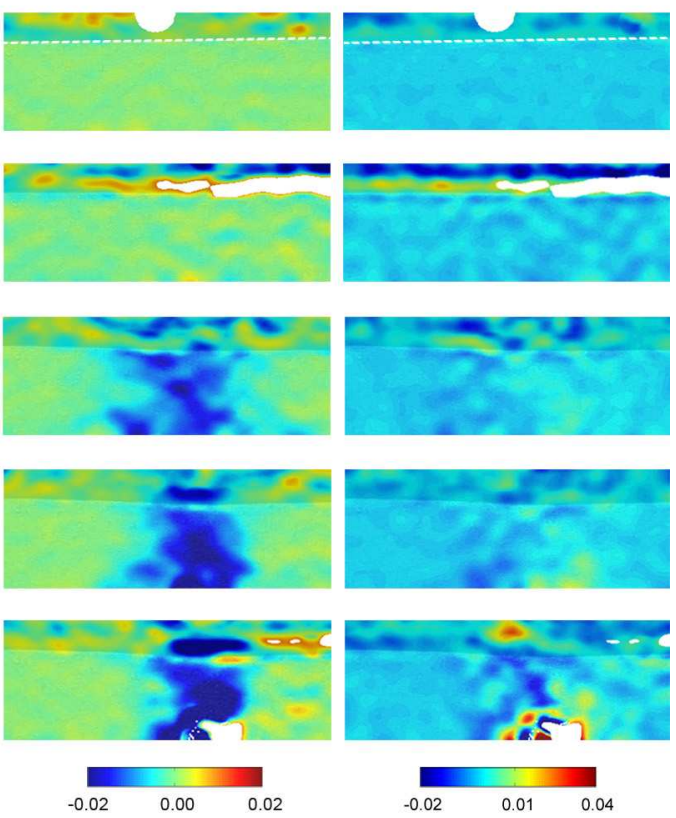

(d)

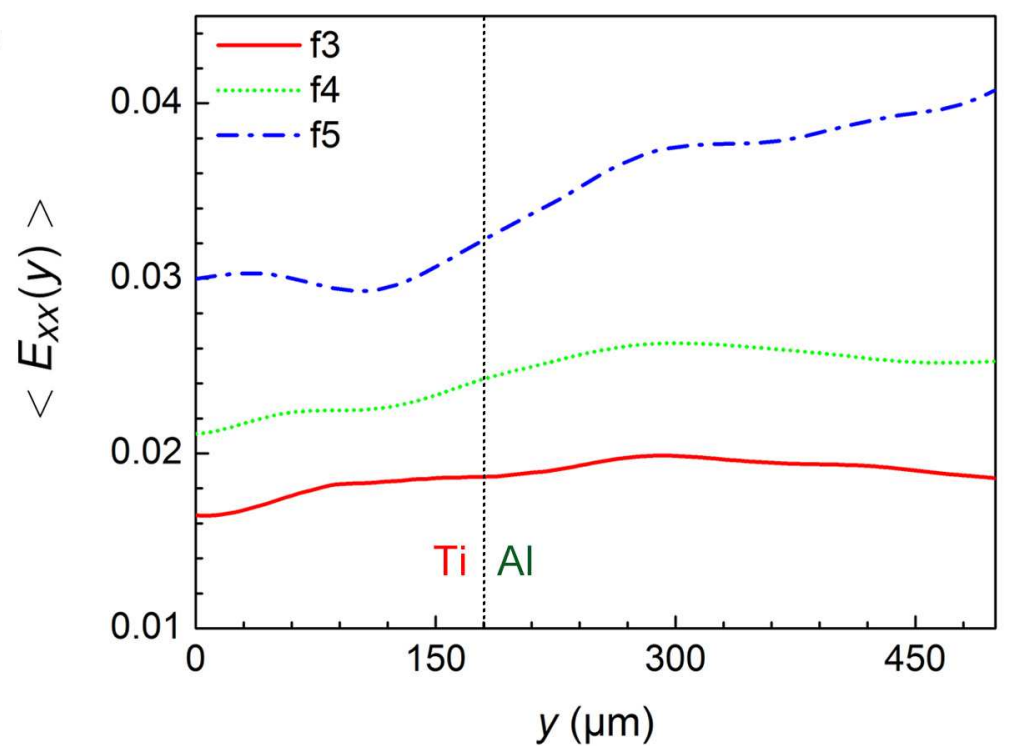

Figure 7: Quasi-static tension parallel to the Ti/Al interface (Ti/Al-0). (a) True stress-strain curve (the quasi-static curve for Ti/Al-90 is also included for comparison). Numbers denote strain rate in s ${ }^{-1}$. (b) Snapshots at instants marked with dots in (a). (c) 2D strain fields $E_{x x}, E_{y y}$ and $E_{x y}$. Dashed lines at frame f1 depicts the Ti/Al interface. White spots denote poor correlation in XDIC. (d) $\left\langle E_{x x}(y)\right\rangle$ profiles across the interface, corresponding to the region denoted by the rectangle in (c). The vertical dotted line indicates the Ti/Al interface. 
(a)

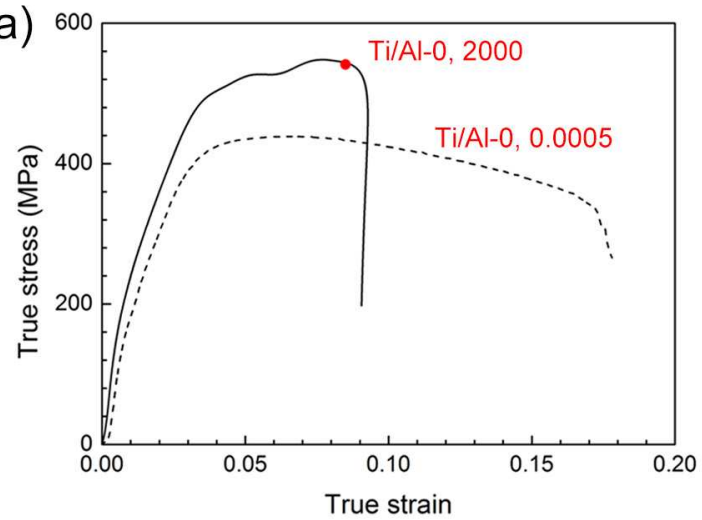

(c)

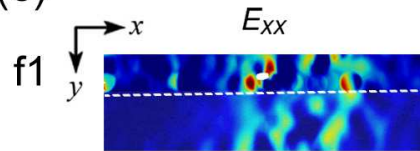

f2

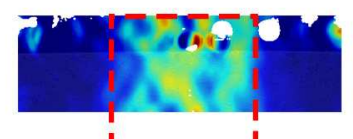

f3

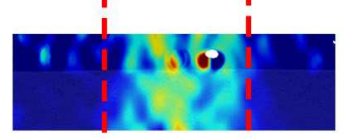

f4

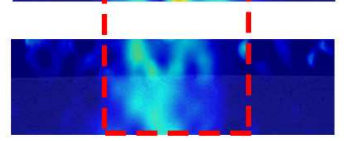

f5

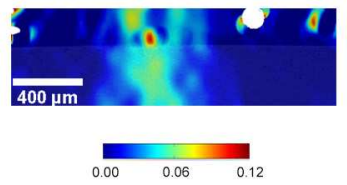

(b)

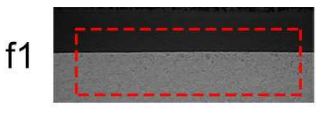

f2

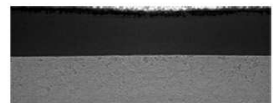

f3

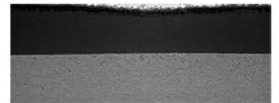

f4

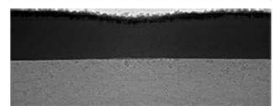

f5

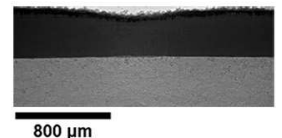

$E_{x y}$
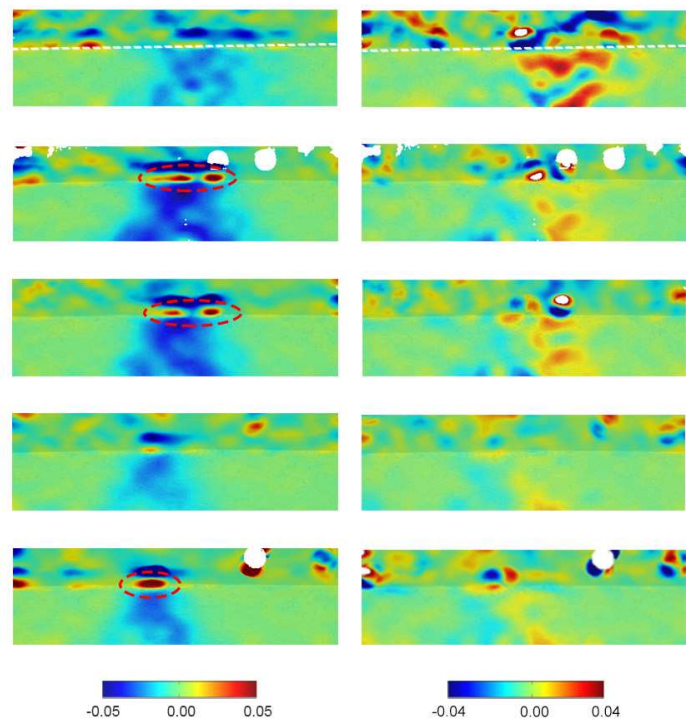

(d)

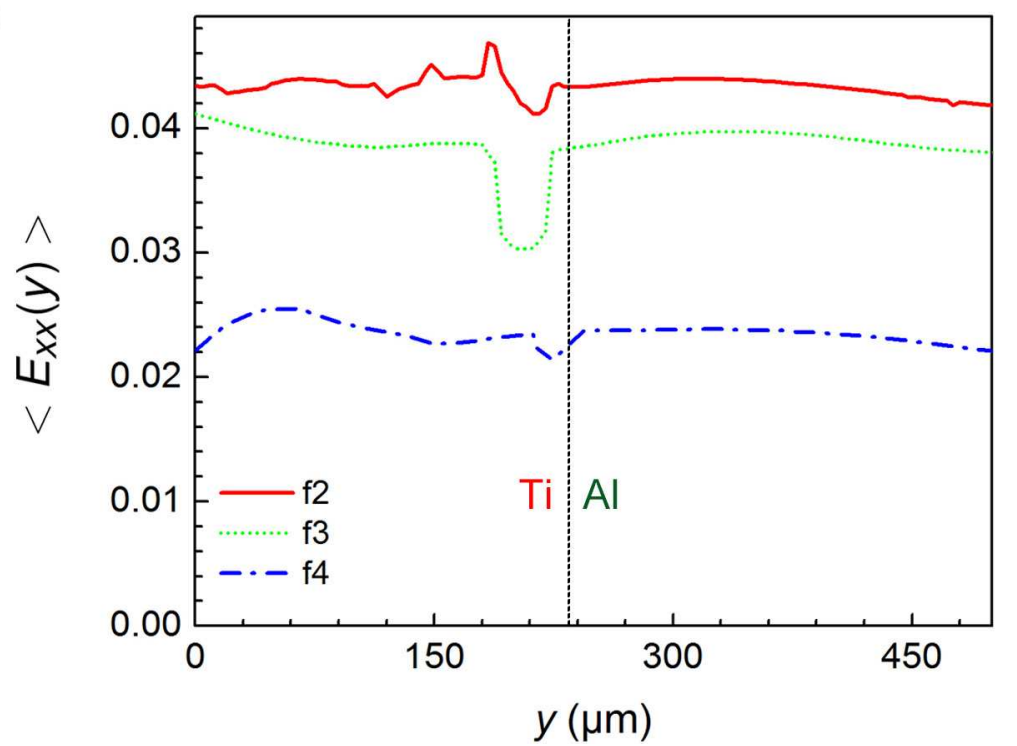

Figure 8: Dynamic tension parallel to the Ti/Al interface (Ti/Al-0). (a) True stress-strain curve (the quasi-static curve is also included for comparison). Numbers denote strain rate in $\mathrm{s}^{-1}$. (b) Snapshots at instants marked with dots in (a). (c) $2 \mathrm{D}$ strain fields $E_{x x}, E_{y y}$ and $E_{x y}$. Dashed lines at frame f1 depict the Ti/Al interface. White spots denote poor correlation in XDIC. (d) $\left\langle E_{x x}(y)\right\rangle$ profiles across the interface, corresponding to the region denoted by the rectangle in (c). The vertical dotted line indicates the Ti/Al interface. 
in the $\mathrm{Al}$ layer, away from the $\mathrm{Ti} / \mathrm{Al}$ interface, and form an apparent deformation band inclined at an angle of $\sim 50^{\circ}$ with the loading direction. $E_{y y}$ is negative (compressional) as a result of Poisson's effect. The strain values in the deformation band is 25 much larger than the bulk strain. At frame f4, the deformation band becomes narrower in space and higher in strain amplitudes (marked by dashed lines) as strain localization proceeds further at the same location, resulting in a stress drop (softening) in the stress-strain curve (Fig. 5(a)). Microcracks coalesce 255 into a macrocrack at frame f5, consequently leading to tensile and shear failure of sample. White spots appear in the fracture region due to deteriorated image correlation at severe plastic deformation. The results show that the Ti/Al interface is stronger than Al. The explosive welding indeed yields a well-jointed $\mathrm{Ti} / \mathrm{Al}$ interface.

To further illustrate the interface's role in deformation and failure of the Ti/Al-90 samples under quasi-static loading, we calculate the $\left\langle E_{x x}(x)\right\rangle$ profiles across the interface within the region labeled by the rectangle (Fig. 5(d)). Here, $\left\langle E_{x x}(x)\right\rangle$ refers to the tensile strains averaged over the $y$-axis. The average 265 strain values in the Ti layer remains around zero, and little plastic deformation is observed in Ti throughout the loading process. The stress in the sample is much lower than the yield stress of Ti. The Ti/Al interface blocks dislocations emitted from $\mathrm{Al}$ after yield, which contribute partly to the increased 270 yield strength of $\mathrm{Ti} / \mathrm{Al}$ compared to $\mathrm{Al}[42,44]$ (Fig. 4); the increase in the effective modulus (Ti/Al versus $\mathrm{Al}$ ) is another factor explained by the general mixture rule of composites [41]. The strain values in the Al layer increases significantly from $\mathrm{f} 2$ to $\mathrm{f} 3$, corresponding to the formation of the deformation band.275 At frame f4, the rising and falling edges of the strain peak become steeper, owing to further strain concentration. Statistical analysis becomes inaccurate at frame f5 (not shown) because of poor correlations.

The stress-strain curve under dynamic loading is similar to 280 that under quasi-static loading, whereas the fracture strain under dynamic loading is much higher than that under quasi-static loading (Fig. 6(a)). This can be well explained by the strain maps (Fig. 6(c)) and $\left\langle E_{x x}(x)\right\rangle$ profile (Fig. 6(d)). The x-ray images show that deformation and fracture are also dominated by 285 the Al layer. But multiple cracks instead of a single macrocrack lead to the final failure. At frame f1, the strain distribution is homogeneous in both the Ti and Al layers (Figs. 6(c) and 6(d)). At frame f2 (beyond the yield point), strain increases simultaneously across the Al layer, and most areas are subjected to 290 apparent tension. This may be attributed to simultaneous nucleation of deformation zones by an elevated driving force, given shorter nucleation/growth time, under impact loading [45].

At frame $\mathrm{f} 3$, slight strain localization occurs in the Al layer. However, no deformation bands are observed until frame $f 4,295$ and the deformation band is different from that in quasi-static loading (Fig. 5(c), frame f4). The strain gradients around the deformation band are smaller than those under quasistatic loading. The corresponding $\left\langle E_{x x}(x)\right\rangle$ profile also exhibits ramped rising and falling edges with multiple peaks, even ${ }_{30}$ though deformation bands have nucleated (Fig. 5(d)). At frame f5, two intersected deformation bands (marked by dashed lines) lead to final failure of the sample, different from the single deformation band under quasi-static loading. Simultaneous development of multiple deformation bands lead to a higher bulk strain, and thus a higher fracture strain of Ti/Al-90 samples compared to those samples under quasi-static loading, since strain localization is diffused and the material is effectively more ductile. The plastic deformation of Ti/Al-90 samples is mainly dominated by the Al layer under both quasi-static and dynamic loading. That explains why the stress-strain curves of Ti/Al-90 samples show slight sensitivity to strain rates.

\subsection{Tension parallel to the interface (Ti/Al-0)}

The stress-strain curve of Ti/Al-0 under quasi-static loading is presented in Fig. 7(a), along with the quasi-static curve of Ti/Al-90 for comparison. Apparent yield strength and failure strain/ductility are much higher for the parallel loading than for the perpendicular loading. The x-ray images (Fig. 7(b)) show that significant necking occurs in the $\mathrm{Al}$ layer at frame $\mathrm{f} 3$, and is much more pronounced than that in the Ti layer. The Ti/Al interface exhibits slight downward curvature (f4 and f5) because of the difference in Poisson's contraction along the $y$-axis between the $\mathrm{Ti}$ and $\mathrm{Al}$ layers. This inflection accommodates the compressional strain in the $y$-direction, and cracking is not observed at the interface.

Fig. 7(c) shows the strain maps at selected instants, where the white spots represent the regions with poor image correlation. For quasi-static tension parallel to the interface, $E_{x x}$ across the $\mathrm{Ti}$ and $\mathrm{Al}$ layers is expected to be equal before necking; consistently, the strain fields at frames $\mathrm{f} 1$ and $\mathrm{f} 2$ are homogeneous. Slight strain localization occurs at frame $\mathrm{f} 3$, and develops into a deformation band at frame $\mathrm{f} 4$. However, the deformation band is blocked by the Ti/Al interface. Fig. 7(d) shows the increase in strain gradients across the interface from nearly zero at frame f3 to substantial at frame f5. Significant strain localization occurs in the $\mathrm{Al}$ layer, but not in the $\mathrm{Ti}$ layer. The $\mathrm{Ti} / \mathrm{Al}$ interface blocks the propagation of the deformation band and delay the failure of samples, leading to higher fracture strain in Ti/Al-0 than Ti/Al-90.

During dynamic loading parallel to the Ti/Al interface, the Ti/Al-0 sample does not fracture during the first loading pulse, and the stress drop in the stress-strain curve (Fig. 8(a)) is caused by subsequent unloading rather than failure. However, higher strain rate leads to higher apparent yield stress (Fig. 8(a)), owing to the rate-sensitivity in yield stress for Ti, as opposed to the insensitivity for Al. Such a rate sensitivity was observed for Ti alloys [46, 47]. This is in contrast with the perpendicular loading case (Fig. 6(a)), where the apparent insensitivity to rate for Ti/Al-90 is due to that for $\mathrm{Al}$.

To examine deformation and fracture of Ti/Al-0 under dynamic loading, $x$-ray images during the first three loading pulses are shown in Fig. 8(b), and the XDIC results, in Fig. 8(c). The strain maps show that pronounced plastic deformation occurs in the Ti layer besides the Al layer. $\left\langle E_{x x}(y)\right\rangle$ is approximately equal for the $\mathrm{Ti}$ and $\mathrm{Al}$ layers (Fig. 8(d)). However, obvious tensile strain (marked by dashed ellipses) is observed across the $\mathrm{Ti} / \mathrm{Al}$ interface along the $y$-axis at frames $\mathrm{f} 2$ and $\mathrm{f} 3$, and interface fracture occurs. Given the rapid loading, the Ti 
and Al layers appear to deform "separately" and the interface fails to accommodate the difference in Poisson's contraction as ously in the $\mathrm{Ti}$ and $\mathrm{Al}$ layers, whereas they act as a whole during quasi-static loading (Fig. 7). Interface cracking leads to considerable strain heterogeneity around the interface, and thus dips ${ }^{360}$ in mean strain profiles of Ti layer (Fig. 8(d)). This is distinct from that observed in Fig. 7(d) where the strain profiles of $\left\langle E_{x x}(y)\right\rangle$ are smooth. The mean strain at frame $\mathrm{f} 4$ is smaller than those at frames f2 and f3 (Fig. 8(d)) because the second pulse ${ }^{365}$ is weaker than the first pulse due to energy dissipation during plastic deformation of materials.

\section{Conclusions}

Explosion-welded Ti/Al bimetal plates exhibit smooth, welljointed, interface. Dynamic and quasi-static uniaxial tension ${ }^{375}$ experiments are conducted on $\mathrm{Ti} / \mathrm{Al}$ with the loading direcconjunction with time-resolved synchrotron $\mathrm{x}$-ray imaging and strain field mapping. Stress-strain curves are obtained along ${ }^{380}$ with time-resolved strain field maps. Ti/Al shows pronounced anisotropy in yield strength, ductility and rate sensitivity. Defor perpendicular loading, while for parallel loading, $\mathrm{Ti}$ and $\mathrm{Al}^{385}$ layers, and the interface are all involved. The rate sensitivity of $\mathrm{Ti} / \mathrm{Al}$ follows those of the constituent metals. For perpendicular loading, strain mapping demonstrates that single deformamultiple deformation bands nucleate simultaneously under dynamic loading, which result in a higher dynamic fracture strain (0.12) than quasi-static loading (0.06). For parallel loading, the interface blocks deformation-band propagation, reduces strain ${ }^{395}$ localization and gives rise to increased ductility of Ti/Al under quasi-static loading, while interface fracture occurs under dynamic loading because of unbalanced Poisson contraction between $\mathrm{Ti}$ and $\mathrm{Al}$ layers.

\section{Acknowledgements}

This work was partially supported by the 973 Project (2014CB845904), and National Natural Science Foundation (11472253) of China. Use of the Advanced Photon Source, an Office of Science User Facility operated for the US Depart-410 ment of Energy (DOE) Office of Science by Argonne National Laboratory, was supported by the US DOE under Contract No. DE-AC02-06CH11357.

\section{References}

[1] Z. Tang, N. a. Kotov, S. Magonov, B. Ozturk, Nanostructured artificial $_{420}$ nacre., Nat. Mater. 2 (6) (2003) 413-418.
[3] A. Finnemore, P. Cunha, T. Shean, S. Vignolini, S. Guldin, M. Oyen, U. Steiner, Biomimetic layer-by-layer assembly of artificial nacre, Nat. Commun. 3 (July) (2012) 966.

[4] A. Fuji, K. Ameyama, T. H. North, Influence of silicon in aluminium on the mechanical properties of titanium/aluminium friction joints, J. Mater. Sci. 30 (20) (1995) 5185-5191.

[5] J. G. Luo, V. L. Acoff, Using cold roll bonding and annealing to process Ti/Al multi-layered composites from elemental foils, Mater. Sci. Eng. A 379 (1-2) (2004) 164-172.

[6] Y. C. Chen, K. Nakata, Microstructural characterization and mechanical properties in friction stir welding of aluminum and titanium dissimilar alloys, Mater. Des. 30 (3) (2009) 469-474.

[7] B. A. Roeder, C. T. Sun, Dynamic penetration of alumina/aluminum laminates: Experiments and modeling, Int. J. Impact Eng. 25 (2) (2001) 169185.

[8] P. Wang, L. R. Xu, Convex interfacial joints with least stress singularities in dissimilar materials, Mech. Mater. 38 (11) (2006) 1001-1011.

[9] X. Sun, M. A. Khaleel, Dynamic strength evaluations for self-piercing rivets and resistance spot welds joining similar and dissimilar metals, Int. J. Impact Eng. 34 (10) (2007) 1668-1682.

[10] A. Tasdemirci, I. W. Hall, Development of novel multilayer materials for impact applications: A combined numerical and experimental approach, Mater. Des. 30 (5) (2009) 1533-1541.

[11] T. Yokoyama, K. Nakai, Determination of the impact tensile strength of structural adhesive butt joints with a modified split Hopkinson pressure bar, Int. J. Adhes. Adhes. 56 (2014) 13-23.

[12] V. Saprygin, E. Karakozov, Y. Bereznikov, Pressure welding of aluminium-steel and titanium-aluminium transition elements for operation at low temperatures, Svar. Proizvod (1975) 21-23.

[13] N. Kahraman, B. Gulenc, F. Findik, Corrosion and mechanicalmicrostructural aspects of dissimilar joints of Ti-6Al-4V and $\mathrm{Al}$ plates, Int. J. Impact Eng. 34 (8) (2007) 1423-1432.

[14] H.-b. Xia, S.-g. Wang, H.-f. Ben, Microstructure and mechanical properties of Ti/Al explosive cladding, Mater. Des. 56 (2014) 1014-1019.

[15] D. Fronczek, J. Wojewoda-Budka, R. Chulist, A. Sypien, A. Korneva, Z. Szulc, N. Schell, P. Zieba, Structural properties of Ti/Al clads manufactured by explosive welding and annealing, Mater. Des. 91 (2016) 8089.

[16] F. Findik, Recent developments in explosive welding, Mater. Des. 32 (3) (2011) 1081-1093.

[17] L. J. Zhang, Q. Pei, J. X. Zhang, Z. Y. Bi, P. C. Li, Study on the microstructure and mechanical properties of explosive welded 2205/X65 bimetallic sheet, Mater. Des. 64 (2014) 462-476.

[18] A. J. Moffat, P. Wright, L. Helfen, T. Baumbach, G. Johnson, S. M. Spearing, I. Sinclair, In situ synchrotron computed laminography of damage in carbon fibre-epoxy [90/0]s laminates, Scripta Mater. 62 (2) (2010) $97-$ 100 .

[19] T. Li, D. Fan, L. Lu, J. Y. Huang, J. C. E, F. Zhao, M. L. Qi, T. Sun, K. Fezzaa, X. H. Xiao, X. M. Zhou, T. Suo, W. Chen, Y. L. Li, M. H. Zhu, $\mathrm{S}$. N. Luo, Dynamic fracture of $\mathrm{C} / \mathrm{SiC}$ composites under high strain-rate loading: microstructures and mechanisms, Carbon 91 (2015) 468-478.

[20] S. McDonald, L. Schneider, A. Cocks, P. Withers, Particle movement during the deep penetration of a granular material studied by X-ray microtomography, Scr. Mater. 54 (2) (2006) 191-196.

[21] S. McDonald, N. Ravirala, P. Withers, A. Alderson, In situ threedimensional X-ray microtomography of an auxetic foam under tension, Scr. Mater. 60 (4) (2009) 232-235.

[22] A. Den Bakker, X. Wu, L. Katgerman, S. Van der Zwaag, Microstructural and $\mathrm{X}$-ray tomographic analysis of damage in extruded aluminium weld seams, Mater. Sci. Technol. 31 (1) (2015) 94-104.

[23] B. Song, B. R. Antoun, H. Jin, Dynamic tensile characterization of a 4330-v steel with kolsky bar techniques, Exp. Mech. 53 (9) (2013) 1519 1529.

[24] D. Fan, L. Lu, B. Li, M. L. Qi, J. C. E, F. Zhao, T. Sun, K. Fezzaa, W. Chen, S. N. Luo, Transient X-ray diffraction with simultaneous imaging under high strain-rate loading, Rev. Sci. Instrum. 85 (2014) 113902.

[25] B. X. Bie, J. Y. Huang, B. Su, L. Lu, D. Fan, J. C. E, T. Sun, K. Fezzaa, M. L. Qi, S. N. Luo, Dynamic tensile deformation and damage of B4Creinforced Al composites: Time-resolved imaging with synchrotron $\mathrm{x}$ rays, Mater. Sci. Eng. A 664 (2016) 86-93.

[26] S. A. Hall, D. M. Wood, E. Ibraim, G. Viggiani, Localised deformation Multi layered structure with strain gradient, Adv. Funct. Mater. 19 (7) (2009) 1054-1059. 
patterning in 2D granular materials revealed by digital image correlation, Granul. Matter 12 (1) (2010) 1-14.

[27] J. Y. Huang, Y. Li, Q. C. Liu, X. M. Zhou, L. W. Liu, C. L. Liu, M. H Zhu, S. N. Luo, Origin of compression-induced failure in brittle solids under shock loading, Phys. Rev. B 92 (14) (2015) 144101.

[28] L. Lu, D. Fan, B. X. Bie, X. X. Ran, M. L. Qi, N. Parab, J. Z. Sun, H. J. Liao, M. C. Hudspeth, B. Claus, K. Fezzaa, T. Sun, W. Chen, X. L. Gong, S. N. Luo, Note: Dynamic strain field mapping with synchrotron X-ray digital image correlation, Rev. Sci. Instrum. 85 (7) (2014) 076101.

[29] H. Huang, J. Yan, New insights into phase transformations in single crystal silicon by controlled cyclic nanoindentation, Scripta Mater. 102 (2015) 35-38.

[30] M. Hudspeth, B. Claus, S. Dubelman, J. Black, A. Mondal, N. Parab, C. Funnell, F. Hai, M. Qi, K. Fezzaa, et al., High speed synchrotron x-ray phase contrast imaging of dynamic material response to split hopkinson bar loading, Rev. Sci. Instru. 84 (2) (2013) 025102.

440 [31] S. Cottrino, Y. Jorand, E. Maire, J. Adrien, Characterization by X-ray tomography of granulated alumina powder during in situ die compaction, Mater. Charact 81 (2013) 111-123.

[32] B. Crossland, Development of exlosive welding and its application in engineering, Metals Mater. 5 (12) (1971) 402-413.

445 [33] D. G. Brasher, D. J. Butler, Explosive welding: principles and potentials, Adv. Mater. Process. 147 (3).

[34] S. A. Mousavi, P. F. Sartangi, Experimental investigation of explosive welding of cp-titanium/aisi 304 stainless steel, Mater. Des. 30 (3) (2009) $459-468$.

450 [35] F. Grignon, D. Benson, K. Vecchio, M. Meyers, Explosive welding of aluminum to aluminum: analysis, computations and experiments, Int. J. Impact Eng. 30 (10) (2004) 1333-1351.

[36] R. Mendes, J. Ribeiro, a. Loureiro, Effect of explosive characteristics on the explosive welding of stainless steel to carbon steel in cylindrical con-

455 figuration, Mater. Des. 51 (2013) 182-192. of explosive joints: Example of titanium to steel cladding, Mater. Sci. Eng. A 528 (6) (2011) 2641-2647.

[38] K. Nemoto, T. Miyaguchi, H. Maruyama, M. Aketagawa, K. Yanagi, I. Yoshida, M. Uchidate, Development of a roughness measurement standard with irregular surface topography for improving 3D surface texture measurement, Meas. Sci. Technol. 20 (8) (2009) 084023.

[39] J. Y. Huang, L. Lu, D. Fan, T. Sun, K. Fezzaa, S. L. Xu, M. H. Zhu, S. N. Luo, Heterogeneity in deformation of granular ceramics under dynamic loading, Scripta Mater. 111 (2016) 114-118.

[40] H. Kolsky, Stress waves in solids, Vol. 1098, Courier Corporation, 1963.

[41] W. D. Callister, D. G. Rethwisch, Materials science and engineering: an introduction, Vol. 7, Wiley New York, 2007.

[42] R. Smerd, S. Winkler, C. Salisbury, M. Worswick, D. Lloyd, M. Finn, High strain rate tensile testing of automotive aluminum alloy sheet, Int. J. Impact Eng. 32 (1-4) (2005) 541-560.

[43] J. L. Yu, J. R. Li, S. S. Hu, Strain-rate effect and micro-structural optimization of cellular metals, Mech. Mater. 38 (1-2) (2006) 160-170.

[44] T. Mukai, K. Higashi, S. Tsuchida, S. Tanimura, Influence of strain rate on tensile properties in some commercial aluminum alloys., J. Japan Inst. Light Met. 43 (1993) 252-257.

[45] Y. Cai, J. Y. Huang, H. A. Wu, M. H. Zhu, W. A. Goddard, S. N. Luo, Tensile Strength of Liquids: Equivalence of Temporal and Spatial Scales in Cavitation, J. Phys. Chem. Lett. 7 (5) (2016) 806-810.

[46] J. Zhang, Y. Wang, Effect of strain rate on the tension behavior of Ti6.6Al-3.3Mo-1.8Zr-0.29Si alloy at low temperatures, Mater. Sci. Eng. A 605 (2014) 59-64.

[47] W.-S. Lee, C.-W. Chen, Dynamic mechanical properties and microstructure of Ti-6Al-7Nb biomedical alloy as function of strain rate, Mater. Sci. Technol. 29 (9) (2013) 1055-1064. 